\title{
Bernabé Aldeguer Cerdá y Gema Pastor Albaladejo (dirs.)(2020), Democracia, gobierno y administración pública contemporánea
}

\section{Bernabé Aldeguer Cerdá y Gema Pastor Albaladejo (dirs.)(2020), Democracy, government and contemporary public administration}

\author{
Jaime Rodríguez Alba \\ Universidad Siglo 21 - UNIR (Universidad Internacional de la Rioja) (Argentina - España) \\ ORCID: https://orcid.org/0000-0003-4612-3498 \\ albajaime@hotmail.com
}

\begin{abstract}
NOTA BIOGRÁFICA
Jaime Rodríguez Alba es Doctor en Filosofía por la UNED y tiene un DEA en Sociología por la Universidad Complutense. Profesor de Ética en los diversos posgrados de la Universidad Siglo 21 de Argentina, donde dirige la Licenciatura en Administración Pública. Profesor de Trasparencia y Buen Gobierno en la UNIR (Universidad Internacional de la Rioja), España. Investiga temas de ética aplicada en varios proyectos a nivel internacional.
\end{abstract}

\section{RESUMEN}

Recensión del libro colectivo dirigido por Bernabé Aldeguer Cerdá y Gema Pastor Albaladejo, Democracia, gobierno y administración pública contemporánea. Madrid. Tecnos 2020. 408 pp.

\section{PALABRAS CLAVE}

Democracia; Gobierno; Administración Pública; Políticas Públicas; Burocracia.

\begin{abstract}
Review of the collective book directed by Bernabé Aldeguer Cerdá y Gema Pastor Albaladejo, Democracy, government and contemporary public administration. Madrid. Tecnos 2020. 408 pp.
\end{abstract}

\section{KEYWORDS}

Democracy; Government; Public Administration; Public Policies; Bureaucracy.

La obra que dirigen los profesores Bernabé Aldeguer Cerdá y Gema Pastor Albaladejo presenta temas tópicos de los estudios de administración pública (modelos de gestión pública, procesos de gestión humana, dirección pública, gobernanza territorial, buen gobierno, trasparencia, rendición de cuentas, partenariados público-privados, uso de las TIC e innovación pública, cambio organizacional, etc.) de forma coherente y apelando a la recuperación de una mirada pluralista que invoca a la diferencia, la diversidad, pero en especial a la conquista del estado por parte de la ciudadanía en sus modulaciones. Una obra que además compila resultados de investigación de los diversos autores.

Ambos directores son profesores de Ciencia Política y de la Administración. Bernabé Aldeguer es profesor en la Universidad de Valencia, Gema Pastor en la Universidad Complutense de Madrid, donde 
GAPP. Nueva Época - N. ${ }^{2}$ 28, marzo 2022 - ISSN: 1989-8991 - DOI: https://doi.org/10.24965/gapp.i28.11032 - [Págs. 143-146]

Bernabé Aldeguer Cerdá y Gema Pastor Albaladejo (dirs.)(2020), Democracia, gobierno y administración pública contemporánea

dirige el Instituto Complutense de Administración Pública. Bernabé se ha destacado con varios premios a lo largo de su formación académica, entre ellos la mención por tercer mejor expediente académico otorgado por el gobierno de España. Ha participado en diversos grupos de investigación y publicaciones en la temática. Por su parte Gema Pastor es referente, en especial en cuestiones de gobierno abierto con enfoques neopúblicos, habiendo escrito numerosas obras en temas de administración pública. Los veintinueve autores que realizan los trabajos de esta obra son también profesionales (profesores e investigadores) de diversas instituciones educativas y de investigación de España y algunos centros extranjeros como la UAEM de México.

La obra que reseño tiene muchas virtudes. La primera de ellas ofrecer un compilado de temas tópicos en el campo de los estudios sobre administración pública (trasparencia, buen gobierno, burocracia, innovación pública, partenariados, gobernanza multinivel, etc.) con un prisma novedoso, pero sobre todo con una capacidad muy grande en sintetizar información actualizada, muy bien estructurada y con hipótesis interpretativas sugerentes. Constituye en este sentido un auténtico manual, fruto de las diversas investigaciones de los autores, que permite en sus veinte capítulos y con los aportes de veintinueve autores ofrecer una panorámica de los temas actuales, ineludible para quien desee tener una visión completa y profunda de las usuales tematizaciones en el campo.

Sin lugar a dudas pese a la diversidad de autores hay una clara línea argumental que sostiene este manual: pensar el nexo entre democracia -procesos de democratización- el gobierno y la administración pública. La clave con la que los diversos autores piensan este nexo, a mi juicio, no puede ser más actual y relevante: apostar por modalidades de interacción entre el estado, la administración pública y los diversos stakeholders que definen sus procesos y relaciones en el marco de los enfoques neopúblicos, desarrollando una visión crítica que integra logros pero ubica riesgos y problemáticas en los enfoques gerencialistas con los que usualmente se considera superar las rigideces de un estado que ha de abrirse para sumarse a los retos que la globalización tecnológica en curso imprime.

El paradigma neopúblico asoma en diversos espacios de la obra, tanto en los más teóricos como en aquellos que describen casos puntuales, generando ideas para dar sustento empírico a los modelos neoweberianos, a las concepciones del nuevo servicio público, a modos de armar gobernanzas colaborativas, innovaciones sustentables, horizontes prácticos para el gobierno abierto, y otros tópicos que la obra aborda. Los trabajos sostienen posturas metodológicas diversas, pues muchos de ellos son de tipo analítico-crítico, otros más de exposición teórico-conceptual, si bien la mayoría recurre a estudios de caso para poder fundamentar las hipótesis e ideas.

La obra se compone de tres partes. La primera -Aproximaciones teóricas para el estudio de gobierno y administración pública- compuesta por ocho capítulos que ahondan en las referencias teóricas que sustentan la mirada neopública de fondo. La segunda -Gobiernos y administraciones públicas en acción- repasa en nueve capítulos tópicos como la trasparencia, el buen gobierno, los partenariados público-privados, las exigencias para una comunicación institucional exitosa, la gobernanza inteligente, el márquetin territorial, la gestión del riesgo, la rendición de cuentas, los procesos colaborativos o el márquetin territorial, entre otros. La tercera parte-Agentes estratégicos para la innovación pública-aglutina en tres capítulos las novedades en temáticas como el empleo público y las competencias profesionales, la alta función pública y los directivos o las interacciones entre grupos de interés y administración pública. Exploremos brevemente cada una de estas partes.

En la primera parte de esta obra se puede visualizar de modo claro el enfoque teórico y las apuestas epistemológicas y políticas de los autores y sus trabajos. Bernabé Aldeguer y Gema Pastor reivindican en su trabajo -El estado en acción- el marco general del enfoque neopúblico con el que se piensa la reestatalización que sugiere la obra. Luz Muñoz Márquez y Juan Antón Mellón -Política, administración pública y democracia- ahondan en la usual contraposición burocracia/gerencia, señalando la necesidad de democratizar y generar espacios participativos que superen enfoques tradicionales (burocráticos 0 gerencialistas). Joan Baptista Harguideguy y Cristina Fernández Rivera -La ciencia de las políticas en el análisis de las políticas públicas-apuestan por el pluralismo analítico y la apertura epistemológica para una institucionalidad reflexiva que democratice el ciclo de las políticas públicas. Ángel Iglesias -Nueva Gestión Pública e innovación en el sector público- explora la necesidad de una innovación que se sustente en estrategias de alianza que presten especial atención a los impactos de las innovaciones, más allá de enfoques puramente resultadistas. Ángel Valencia Sáiz y Bernabé Aldeguer Cerdá -Tecnocracia y gestión pública- consideran central para la democratización auspiciada en la obra una refundación de la estatalidad orientada a superar el gerencialismo y la tecnocracia de modelos previos. Cristina Ares Castro- 
GAPP. Nueva Época - N. ${ }^{2}$ 28, marzo 2022 - ISSN: 1989-8991 - DOI: https://doi.org/10.24965/gapp.i28.11032 - [Págs. 143-146]

Bernabé Aldeguer Cerdá y Gema Pastor Albaladejo (dirs.)(2020), Democracia, gobierno y administración pública contemporánea

Conde -Gobernanza multinivel en el marco de la Unión Europea- analizando el concepto de gobernanza y su interacción con la presencia de múltiples niveles decisionales y administrativos, estima que se precisa repolitizar espacios de gobernanza en la Unión Europea, considerando el actual método comunitario. Finalmente Gema Pastor Albaladejo, Gema Sánchez Medero y Pilar Mairal Medina -Nuevo servicio público y gobierno abierto- dan un cierre coherente a esta primera parte, estimando las metodologías del gobierno abierto en la senda democratizadora de este enfoque neopúblico que estudian en los autores del Nuevo Servicio Público. De tal modo ponen foco en lo que son claves hermenéuticas de la obra: la deliberación, la co-gestión, la co-dirección, etc., y los procesos de trasformación cultural necesarios para superar modelos gerencialistas.

La segunda parte de la obra arranca con las consideraciones de Laura Román Masedo -Buen gobierno y trasparencia- relativas a la equivocidad de los conceptos de buen gobierno y de trasparencia así como las dificultades metodológicas del diseño de indicadores y dimensiones para la implementación de los mismos. María Ángeles Abellán López y Gonzalo Pardo Beneyto -Rendición de cuentas y control del gasto público- consideran central en el control del gasto público la receptividad social, así como la apuesta por modalidades de public compliance y la articulación de los programas y acciones de las entidades de fiscalización superior con los sistemas de rendición de cuenta de instituciones y gobiernos. Oscar Diego Bautista -Ética pública y gestión de integridad- presenta los instrumentos éticos que conforman un Sistema Ético Integral (SEI), señalando la importancia de la profesionalización en la gestión ética, así como la supervisión cívica. Irene Belmonte Martín y María José García Solana -Gestión pública y gestión privadaen sintonía con el marco general de la obra consideran la inserción de los partenariados público-privados en el marco del gobierno abierto y una gobernanza orientadas a la co-producción, co-creación y gestión integrada de servicios. Cecilia Güemes y Jorge Resina -Procesos colaborativos- muestran, mediante un estudio empírico asociado al caso de Madrid Escucha, las variables e indicadores que permiten procesos de participación virtuosos, señalando cómo la confianza es clave en el proceso. Rubén Sánchez Mederos - Comunicación Institucional y gestión de la información pública- estima que la democratización y sus exigencias (pluralidad, diversidad, etc.), exigen considerar los sistemas de información y comunicación junto con diseños institucionales permeables a las formas de escucha activa. Gonzalo Pardo Beneyto y María Ángeles Abellán López -TIC e innovación institucional- vinculan la gobernanza inteligente, cuyo desarrollo comporta nuevas tecnologías, a la necesidad de cambios organizacionales. Cambios precisos para domesticar las diversas formas de isomorfismo que pueden desvirtuar la innovación pública. María José Cerdá Bertomeu -Marketing territorial y diplomacia pública- considera que el márquetin territorial es un proceso político que puede convertirse en una herramienta de gestión público para la gobernanza de los territorios. Finaliza esta segunda parte con el trabajo de Roberto Losada Maestro-Gestión del riesgo-, en el que tematiza los elementos éticos presentes en las regulaciones de la complejidad, incertidumbre y ambigüedad presentes en la gestión del riesgo, apostando por la regulación comunitaria como buena opción para la tematización ética.

La tercera parte de esta obra abre con el trabajo de Nieves Ortega Pérez y Margarita Pérez Sánchez -Empleados públicos y competencias profesionales-. Las autoras además de presentar las innovaciones en el empleo público generadas por la nueva regulación del Estatuto Básico del Empleado Público, inciden en profundizar las tendencias hacia un servicio público caracterizado por el desarrollo de nuevas competencias profesionales y la flexibilidad estructural. Jorge Crespo -Alta función pública y directivos públicos- explora la tensión entre administración (técnica) y política (ideología) en su modulación entre una dirección pública y una dirección profesional. Esta tercera parte se cierra con el trabajo de Iván Medina Ibarra y Luis Bouza García -Grupos de interés y administraciones públicas- en el que valoran fenómenos como la cartelización política y el corporativismo. Fenómenos que pueden ser abordados en su complejidad mediante medidas neopúblicas orientadas al reconocimiento de nuevos actores y a una visión abierta y pluralista de la interacción con y entre los mismos.

Más que recomendable esta obra. No sólo por ser un manual al estilo tradicional de puntilla y búsqueda de completud. Sino por el ejercicio coherente en la interpretación de tópicos, usuales en el campo de las ciencias políticas y de la administración, desde una escala de afinidades realmente asombrosa para la multitud de autores que escriben. A lo que ha de sumarse el rigor científico en las fuentes, las referencias epistémicas obligatorias, los debates actuales en liza, etc.

A un lector quisquilloso podría gustarle una introducción general más amplia en la que los directores explorarán la obra que dirigen, si bien es cierto que en el capítulo primero hacen esto de forma concisa. También puede que les sugiriera a los directores que en un manual que pretende analizar la articulación entre es- 
tado, democracia y administración pública contemporánea, se prestara también atención a la deconstrucción de la mirada eurocéntrica, avizorando otras epistemologías, tradiciones institucionales, mirada poscolonial, etc., dado que el manual no delimita el ámbito geográfico de contemporaneidad. Finalmente, si atendemos a un lector escrupuloso de épocas y tendencias tecnológicas, echaría de menos un mayor análisis de los impactos de la smartificación de la gestión pública para las administraciones públicas actuales. No obstante reconocer que en la obra se abordan estos problemas en varios acápites. Pero, por ejemplo, sería positivo una mayor especificidad en la temática de los problemas estratégicos, políticos y éticos, que suponen la ciencia de datos o la inteligencia artificial aplicada en la gestión pública.

Como los directores de la obra -Bernabé Aldeguer Cerdá y Gema Pastor Albaladejo- refieren en el primer capítulo, los destinatarios posibles de esta obra son muchos. Estudiantes, profesores, investigadores, pero también expertos y funcionarios públicos. Por supuesto un manual escrito con la suficiente amplitud de miras como para ser también de uso al lector interesado en temas de la política y el estado. 